\title{
Grain dust and lung health: Not just a nuisance dust
}

\author{
Margaret R Becklake MD
}

$\mathrm{T}_{3}^{\mathrm{h}}$ he invitation to contribute to the present issue of the Journal, celebrating the 50th anniversary of the Canadian Thoracic Society (CTS), provides me with an opportunity to document what, in my view, is one of the most effective collective interventions in the field of epidemiology and occupational health. The present essay gives the reasons why the Society addressed the question of whether grain dust is not just a nuisance dust, and how it did so. My main source of information is from a 1978 report in the Canadian Lung Association Bulletin (1).

Grain growing, handling and processing have long been major Canadian industries. In the 1971 census of Canada, there were in Canada approximately 253,000 farmers, farm managers and farm workers; approximately 5000 small elevator workers and 7200 large elevator workers; and approximately 15,000 workers in the flour, feed and seed mills.

The dust to which grain workers are exposed is complex, whether it be wheat, barley, rye, oats or corn. It consists of the grain, hairs from the epicarp and the germ. Plant contaminants include weeds and pollens. Fungi grow in grain depending on its freshness. Rodents may infest it, leaving their spoor. Chemicals may be added to control fungi, arthropods and rodents. Free silica from the soil may be present or incorporated into the plant as phytoliths. Finally, grain workers often handle oil seeds such as sunflower, flax and mustard.

Grain dust had been classified as a 'nuisance' dust; it does not, in the view of the influential American Conference of Government and Industrial Hygienists, require regulation because of its ill health effects on exposed workers. This, however, was contrary to the experience of several members of the CTS, who had been involved in an impressive number of epidemiological research studies of workers in different branches of the grain handling industry before 1977 .

\section{THE CANADIAN LUNG ASSOCIATION TASK FORCE}

This led the then President of the CTS, Dr Reuben Cherniack, to invite physicians interested in grain dust and its ill effects on health to form a Task Force. Its mandate was to advise the CTS on the present knowledge on health and grain dust; on the most fruitful areas for future study and methodology for early recognition; to consider safety standards; and finally, as a Committee of the CTS, to "provide information to the Society upon which to formulate any views it might express to Government in this area." (See Appendix for a list of the members of the Task Force.)

\section{HEALTH STUDIES OF GRAIN HANDLERS IN CANADA UP TO 1977}

Fourteen studies were published in this period: three studies among farmers in Saskatchewan and Manitoba (approximately 3200 subjects); four studies among country elevator workers in Saskatchewan and Manitoba (approximately 3520 subjects); three studies among workers in large elevators in Ontario, Quebec and British Columbia (approximately 4794 subjects); and four clinical studies in Saskatchewan, Manitoba and Alberta (154 subjects). Health status was evaluated by questionnaire in 13 studies, by lung function testing in 11 studies, by chest $\mathrm{x}$-ray in seven studies, by skin prick tests in six studies and by a variety of other tests in seven studies.

After reviewing these studies in detail, the Task Force developed the following recommendations: there should be standardization of all research methods (including questionnaires, lung function tests, allergen skin test extracts, blood tests and precipitin tests); and all future studies should include environmental measurements, to be made with the assistance of Environment Canada in selecting sampling sites and in carrying out the measurements. The Task Force also strongly endorsed the recommendation of the Finn Commission (1975) that research should be encouraged and that health surveillance should be instituted for grain workers.

\section{HEALTH STUDIES OF GRAIN HANDLERS IN CANADA FROM 1977 TO 1993}

During this period, an impressive series of studies were carried out by members of the CTS all addressing various aspects of the question: "Does exposure to grain dust at work affect health?" These are briefly reviewed in narrative form in the following section, with emphasis on how the research findings successively brought to light new information, culminating in strong recommendations for control of exposure and health surveillance in the Canadian grain handling industry.

An early study (2) published in 1974 entitled "Hypersensitivity reactions to grain dust" described a series of 17 men, all with respiratory symptoms and a history of exposure to grain dust. The purpose of the paper was "to report on the nature of the pulmonary abnormalities resulting from occupational exposure to grain dust, and the role of immunological mechanisms in the production of these abnormalities." Methods of study included questionnaires, lung function tests, skin tests and precipitin tests, as well as an inhalation challenge test using grain dust. After analyzing their data, the authors came to the conclusion that "it is still unclear which

Department of Medicine, Department of Epidemiology, Biostatistics and Occupational Health, McGill University, McGill University Health Centre, Montreal, Quebec

Correspondence: Dr Margaret R Becklake, Department of Medicine, Department of Epidemiology, Biostatistics and Occupational Health, McGill University, McGill University Health Centre, 3650 St Urbain Street, Room K1.33, Quebec H2X 2 P4.

Telephone 514-934-1934 ext 32159, fax 514-843-2083, e-mail margaret.becklake@mcgill.ca 
constituent of grain dust might be the main antigen causing hypersensitivity." Like other studies published in this era in which chest physicians focused on mechanisms of disease, their subjects of study consisted of patients from a specialty clinic.

In a 1980 study (3) entitled "Chronic bronchitis and decreased forced expiratory flow rates in lifetime nonsmoking grain workers," the authors examined the role of grain dust, independent of smoking, using a matched case-control design. To match lifetime nonsmoking grain workers with lifetime nonsmoking nongrain workers (a technique used to control for smoking before regression analyses were commonly used), an initial survey in the area identified a series of nongrain workers from the Saskatchewan Hospital Service plan. These individuals were then approached by members of the Saskatchewan Anti-Tuberculosis League who identified the lifetime nonsmoking nongrain workers. The prevalence of chronic bronchitis was higher in the grain workers than in the controls ( $23.1 \%$ versus $3.3 \% ; \mathrm{P}=0.01$ ), and they had significantly lower maximal midexpiratory flow rates. The authors concluded that "exposure to grain dust in lifetime non-smoking grain workers is associated with an increased prevalence of respiratory symptoms and evidence of airflow obstruction." Also of interest was that six men in the control group turned out to have asthma, whereas there were none among the grain workers. This suggested to the authors a 'healthy' worker effect among the grain workers, one of the first studies to do so.

A 1981 study (4) entitled "A follow-up study of the grain elevator workers in the Port of Vancouver" showed that the prevalence of respiratory symptoms and the decline of lung function over time was similar to that obtained in the first survey in these elevators, even though the dust levels were considerably lower in the second survey. Among the $23.5 \%$ of workers who followed the authors' advice to give up smoking at the first survey, the prevalence of cough and sputum had fallen by the second survey. Among the grain workers, the decline in lung function did not correlate with lung function level at the first survey nor with the presence of respiratory symptoms, atopic status or duration of employment. It did, however, correlate with the changes in lung function over one work shift and over one working week at the first survey. This new and surprising finding suggested to the authors that the acute bronchoconstrictive effect of grain dust may eventually lead to irreversible bronchoconstriction. The authors' final tentative but very important conclusion was that grain dust "should not be regarded as a 'nuisance' dust."

A 1984 study (5) entitled "Host factors affecting longitudinal decline in lung spirometry among grain elevator workers" studied 267 workers in Terminal Elevators in Vancouver who did not change their smoking habits over the six-year period of follow-up. Acute changes in lung function over one work week recorded at the initial survey were, as in the previous study, positively associated with subsequent decline in lung function, as was bronchial hyper-reactivity measured by methacholine. This test, however, was only carried out at the third survey among these grain elevator workers. Also of interest was the fact that the lung function of current smokers, while significantly lower than that of nonsmokers, was not significantly lower than that of the control group of the same smoking habit (civic workers for the city of Vancouver). This led the authors to speculate that nonsmokers are at a greater risk for developing impaired lung function from grain exposure than smokers. An alternate possibility is that smokers are more resistant to the effects of smoking, evidence of the interesting phenomenon of the 'healthy' smoker effect, analogous to the 'healthy' worker effect. As with previous studies, these authors concluded that the then current threshold limit for grain dust $\left(10 \mathrm{mg} / \mathrm{m}^{3}\right.$; ie, the limit for a 'nuisance dust') should be lowered.

In a 1985 study (6) entitled "Rapid decline in $\mathrm{FEV}_{1}$ in grain workers: Relation to level of dust exposure" addressed the same issue as in the previous study using a nested case-control design. The $10 \%$ of workers with the worst trend in forced expiratory volume in $1 \mathrm{~s}\left(\mathrm{FEV}_{1}\right)$ (mean annual decline of $100 \mathrm{~mL}$ ) were significantly more likely to have had a decline over the working week at the initial survey and to have exhibited bronchial hyper-reactivity at the third survey. No relation was found between the OR of being a case and a number of other host factors, including exhibiting immediate skin reactivity to common allergens; a history of asthma, bronchitis or hay fever; or the presence of respiratory symptoms. The authors reiterate the conclusions of the previous two papers that exposure to grain dust at levels greater than $5 \mathrm{mg} / \mathrm{m}^{3}$ is associated with a serious adverse trend in $\mathrm{FEV}_{1}$.

In a 1988 paper (7) entitled "Does seasonal employment in grain elevators increase nonspecific airways responsiveness?", the authors examined 45 grain handlers in the St Lawrence river ports during layoff and again during employment. Airway reactivity was also studied in 56 men of similar age and socioeconomic status who were not exposed to grain dust. Exposure to grain dust and increased airway reactivity have both been associated with increased acceleration in the rate of decline of lung function. The study objective was "to determine whether short-term exposure (to grain dust) increased airway reactivity. Airway reactivity, slightly higher among laid off grain handlers than in the comparison group, decreased more among grain handlers during employment than in the comparison group during the same period of time. The authors concluded that their results did "not support the hypothesis that seasonal exposure to grain dust increases airway reactivity." They also suggest that "a mechanism other than the Dutch hypothesis should be explored." The Dutch hypothesis held that increased airway hyper-responsiveness was a risk factor for chronic obstructive pulmonary disease (COPD) in contrast with the British hypothesis, which implicated chronic mucus secretion as a marker of recurrent infections causing chronic airflow limitation.

In a study (8) entitled "Grain dust and lung function. Doseresponse relationships," the issue implicit in the title was addressed. The authors raised the same issue that was raised in the previous papers, namely whether the allowable exposure level in Canada (then still $10 \mathrm{mg} / \mathrm{m}^{3}$ ) should be lowered. To calculate dust exposures, the authors made use of all the environmental dust samples that had been gathered in the Port of Vancouver Terminal Elevators by, or were available to, Labour Canada in the years 1975, 1976, 1978 through 1982, 1988 and 1989. A total of 781 personal samples representing 20 different job titles were used to construct a job-title-period matrix for average dust exposure levels. The matrix was then applied to obtain a value for estimated cumulative and average dust exposure. Significant dose-response relationships were seen for chronic phlegm, breathlessness on exertion, $\mathrm{FEV}_{1}$ and forced vital capacity (FVC) levels, and longitudinal change. Also, workers with an average estimated exposure between $4 \mathrm{mg} / \mathrm{m}^{3}$ 
and $9 \mathrm{mg} / \mathrm{m}^{3}$ were found to have lower levels for $\mathrm{FEV}_{1}$ and FVC compared with workers exposed to levels of $4 \mathrm{mg} / \mathrm{m}^{3}$ or less, despite no differences in the duration of employment. The authors concluded that their "results show a strong relationship between grain dust exposure and both respiratory symptoms and lung function level and decline, and also suggest that the Canadian allowable exposure level of $10 \mathrm{mg} / \mathrm{m}^{3}$ is too high." This was a very important result that was generated from an elegantly conducted study combining a great amount of data to address a significant public issue.

In a 1992 study (9) entitled "Decline in spirometric variables in grain workers from start of employment: Differential effect of duration of follow up," the authors followed 164 young men, 25 years of age or younger, in an annual surveillance program carried out among all the new grain workers. The number of workers who returned for their annual examination after two, three and four years was 16,31 , and 51 respectively. The decline in their $\mathrm{FEV}_{1}$ from initial values was $224 \mathrm{~mL} /$ year, $130 \mathrm{~mL} /$ year and $70 \mathrm{~mL} /$ year, respectively. Also of interest was the fact that at the initial examination, six workers reported having had asthma; none of these men returned for the second annual examination. The authors note that "studies of dropouts are scarce despite indirect evidence provided by cross-sectional studies for health selection as a factor in dropout." They then go on to conclude, perhaps too cautiously, that "restriction of analysis to the survivors may underestimate the relation between work and respiratory impairment."

A 1992 study (10) entitled "Five cross-sectional studies of grain elevator workers" summarizes the findings in the five studies carried out at three year intervals between 1976 and 1988 at the terminal elevators in British Columbia. Civic workers were studied in the same manner as a referent group. The procedures used included interview-administered questionnaires, spirometry using the same spirometers, allergy skin tests and measurement of dust exposure using personal sampling. Although the dust concentration in the elevators was reduced progressively over the years, grain workers had more respiratory symptoms and lower lung function than the civic workers in each of the five surveys. Exposure to grain dust was associated with a significant reduction of $\mathrm{FEV}_{1}$ and $\mathrm{FVC}$, but not in the maximum midexpiratory flow rates or in the ratio of $\mathrm{FEV}_{1} / \mathrm{FVC} \%$, suggesting that the reduction in volume may be due to lesions in the lung parenchyma or in the small airways.

\section{REFERENCES}

1. Canadian Lung Association Task Force Report on the Health of Grain Workers. CLA Bulletin 1979;4-7.

2. Warren P, Cherniack RM, Tse KS. Hypersensitivity reactions to grain dust. J Allergy Clin Immunol 1974;53:139-49.

3. Dosman JA, Cotton DJ, Graham BL, Li KY, Froh F, Barnett GD. Chronic bronchitis and decreased forced expiratory flow rates in lifetime nonsmoking grain workers. Am Rev Respir Dis 1980;121:11-6.

4. Chan-Yeung M, Schulzer M, Maclean L, et al. A follow-up study of the grain elevator workers in the Port of Vancouver. Arch Environ Health 1981;36:75-81.

5. Tabona M, Chan-Yeung M, Enarson D, et al. Host factors affecting longitudinal decline in lung spirometry among grain elevator workers. Chest 1984;85:782-6.

6. Enarson DA, Vedal S, Chan-Yeung M. Rapid decline in $\mathrm{FEV}_{1}$ in grain workers: Relation to level of dust exposure. Am Rev Respir Dis 1985;132:814-7.
The authors note that "workers who took part in all five surveys tend to be a 'healthier' selected group compared with the civic workers." They conclude that their study has confirmed that grain dust has adverse effects on the lungs and finally that "cross-sectional study of grain workers has proved to be a consistent and useful method to evaluate occupational health hazards." This conclusion should be heartily endorsed given that cross-sectional studies, often called the 'work horse' of occupational epidemiology, tend to be underestimated by researchers and statisticians, especially the latter!

So, with substantial help from members of the CTS, grain dust is now clearly identified as harmful to lung health. In 1996, a paper (11) entitled "Recommendations for reducing the effect of grain dust on the lungs," sponsored by the Standards Committee of the CTS, was published in the Canadian Medical Association Journal, recommending a permissible exposure limit of $5 \mathrm{mg} / \mathrm{m}^{3}$ to control short-term effects of exposure. The report notes that the economic implications of implementing a lower permissible exposure limit have not been evaluated. Evidence was considered insufficient to determine the level needed to prevent long-term effects. The report also notes that there has been no external review of these recommendations. However, the American Conference of Government and Industrial Hygienists now recommends an $8 \mathrm{~h}$ average exposure limit of $4 \mathrm{mg} / \mathrm{m}^{3}$ for wheat, oats and barley. These recommendations were approved by the Standards Committee of the CTS.

It is now time to move on to other questions.

APPENDIX
Canadian Lung Association Task Force Report on the Health of
Grain Workers. Task Force Members: M Ahririi (McGill
University, Montreal, Quebec); MR Becklake (Chair) (McGill
University, Montreal, Quebec); I Broder (Gage Research
Institute, Toronto, Ontario); D Cotton (University of
Saskatchewan, Saskatoon, Saskatchewan); J Dosman (University
of Saskatchewan, Saskatoon, Saskatchewan); S Grzybowski
(Vancouver General Hospital, Vancouver, British Columbia);
FE Hargreave (St Joseph's Hospital, Hamilton, Ontario);
BJ Sproule (University of Alberta, Edmonton, Alberta); K Tse
(University of Manitoba, Winnipeg, Manitoba); CPW Warren
(Secretary) (St Boniface General Hospital, Winnipeg, Manitoba);
M Yeung (Vancouver General Hospital, Vancouver, British
Columbia).

7. Dales RE, Ernst P, Blanchet Y, Bourbeau J. Does seasonal employment in grain elevators increase nonspecific airways responsiveness? J Occup Med 1988;30:613-6.

8. Huy T, De Schipper K, Chan-Yeung M, Kennedy SM. Grain dust and lung function. Dose-response relationships. Am Rev Respir Dis 1991;144:1314-21.

9. Zejda JE, Pahwa P, Dosman JA. Decline in spirometric variables in grain workers from start of employment: Differential effect of duration of follow up. Br J Ind Med 1992;49:576-80.

10. Chan-Yeung M, Dimich-Ward H, Enarson DA, Kennedy SM. Five cross-sectional studies of grain elevator workers. Am J Epidemiol 1992;136:1269-79.

11. Becklake M, Broder I, Chan-Yeung M, et al. Recommendations for reducing the effect of grain dust on the lungs. Canadian Thoracic Society Standards Committee. CMAJ 1996;155:1399-403. 


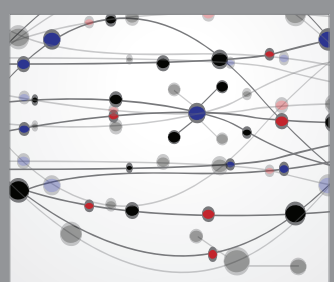

The Scientific World Journal
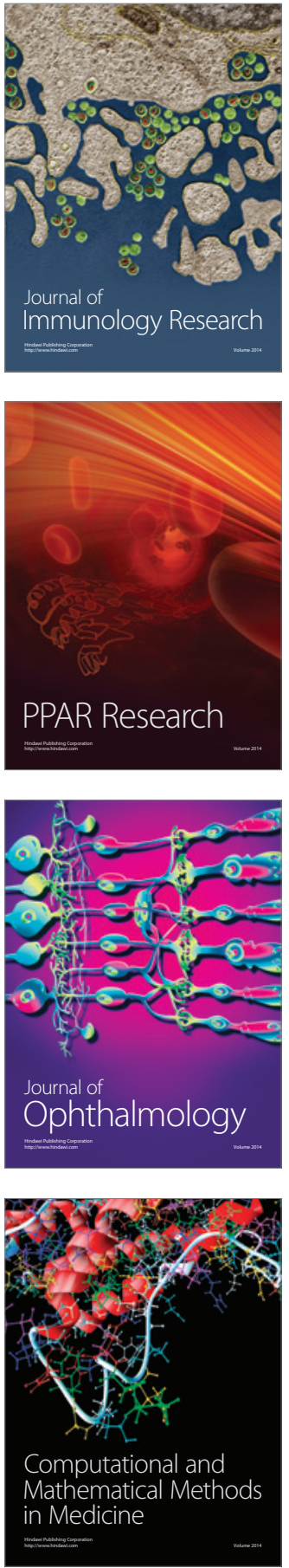

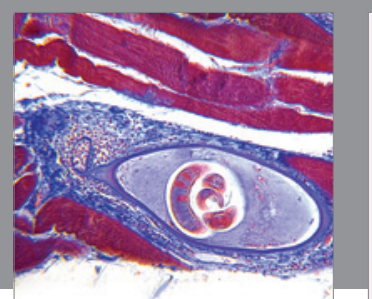

Gastroenterology Research and Practice

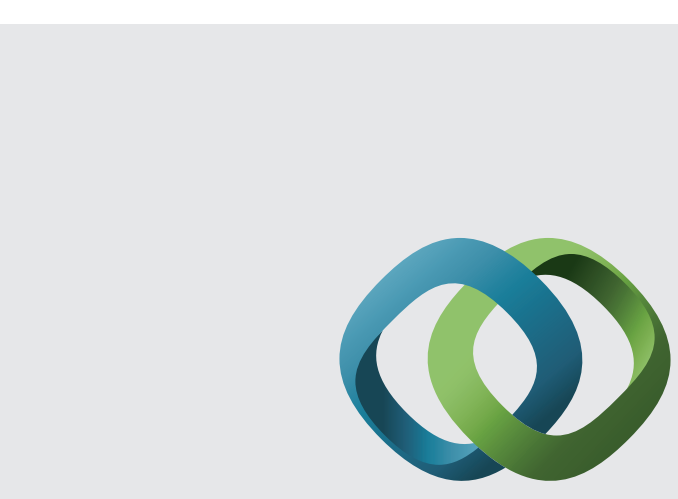

\section{Hindawi}

Submit your manuscripts at

http://www.hindawi.com
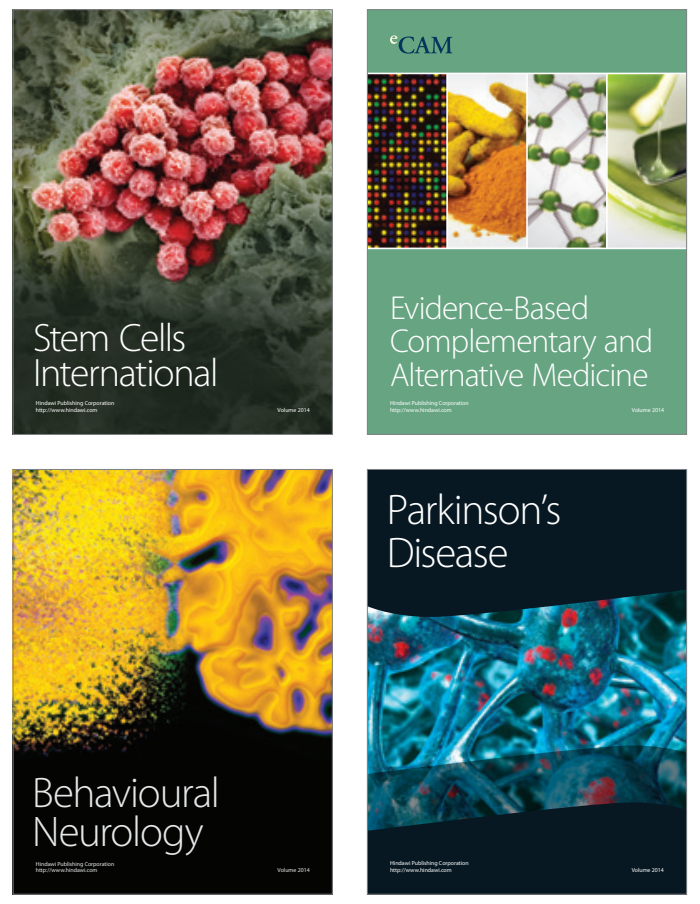
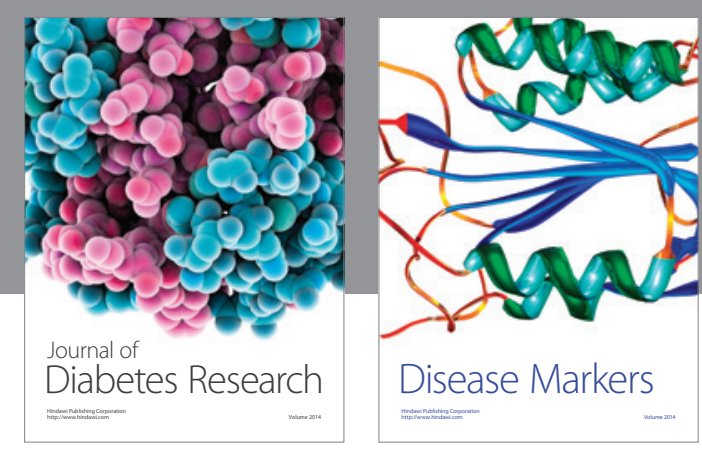

Disease Markers
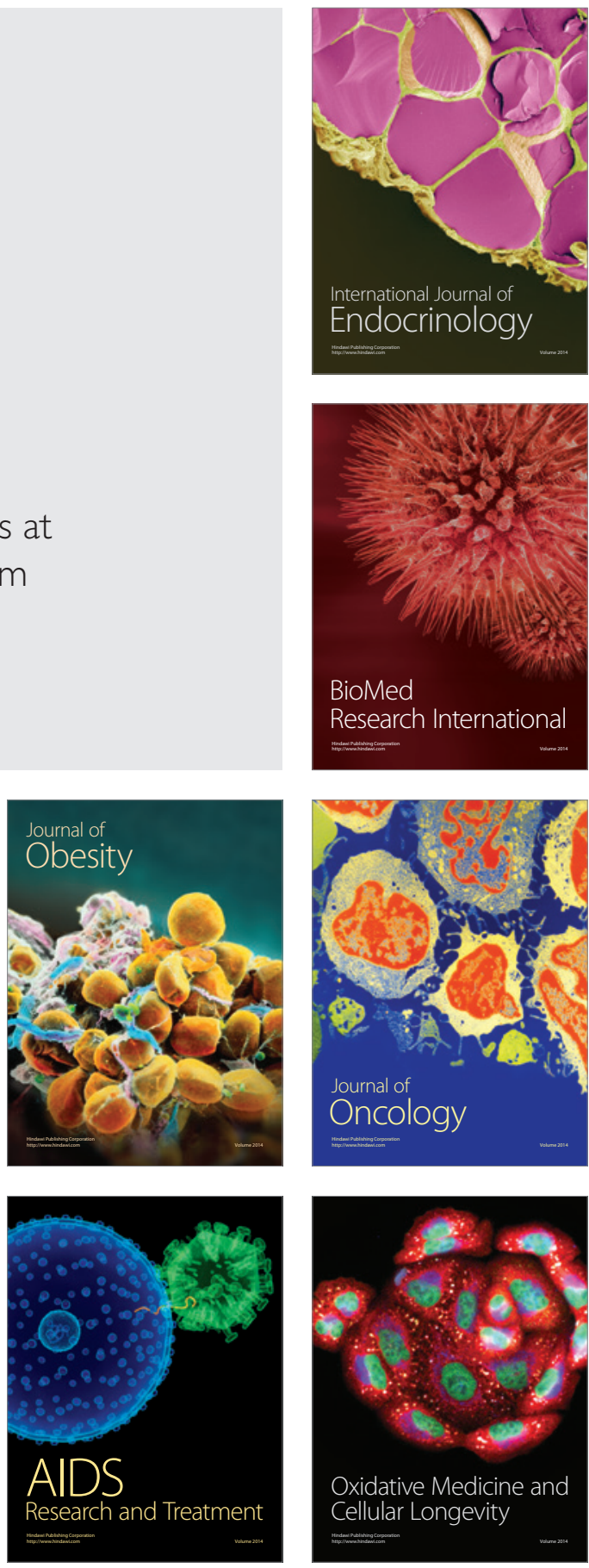